\title{
Ifosfamide as a Cause of Fanconi Syndrome
}

\author{
Review began 02/22/2022 \\ Review ended 02/23/2022 \\ Published 03/01/2022 \\ (c) Copyright 2022 \\ Martinez et al. This is an open access \\ article distributed under the terms of the \\ Creative Commons Attribution License CC- \\ BY 4.0., which permits unrestricted use, \\ distribution, and reproduction in any \\ medium, provided the original author and \\ source are credited.
}

Daniel Martinez ${ }^{1}$, Joaquin Rodelo ${ }^{1,2}$, Sebastian Pelaez García ${ }^{1}$

1. Internal Medicine, Universidad de Antioquia, Medellín, COL 2. Nephrology, Hospital San Vicente Fundación, Medellín, COL

Corresponding author: Daniel Martinez, daniel.martinez2707@gmail.com

\section{Abstract}

Ifosfamide-induced Fanconi syndrome is a rare complication that occurs in patients in treatment with ifosfamide. It is usually characterized by type II proximal renal tubular dysfunction, as evidenced by glycosuria, proteinuria, electrolyte loss, and metabolic acidosis. We outline two case reports of patients who received ifosfamide as chemotherapy for Ewing's sarcoma and extranodal B-cell lymphoma.

Categories: Internal Medicine, Nephrology, Oncology

Keywords: hyperchloremic metabolic acidosis, chemotherapy, glomerulopathy, renal tubulopathy, ifosfamide, fanconi

\section{Introduction}

The reabsorption of many solutes takes place in the proximal renal tubule, with $65 \%$ of sodium, $90 \%$ of glucose, amino acids, bicarbonate, and phosphorus being absorbed there [1]. Fanconi syndrome is associated with inadequate reabsorption in the proximal renal tubule [2]. Different abnormalities lead to its suspicion: amino-aciduria (with losses up to 0.5-1 g/day), glucosuria in absence of hyperglycemia, hypophosphatemia due to reabsorption disruption, natriuresis, kaliuresis, and hyperchloremic metabolic acidosis [1-3].

The most common cause of Fanconi syndrome in adults is exposure to endogenous or exogenous toxins such as heavy metals, drugs, or dysproteinemias. Inborn errors of metabolism are the most common cause in children [1]. Many drugs have been associated with Fanconi syndrome, such as antibiotics, antiviral therapy drugs, anticonvulsants, and chemotherapy drugs such as ifosfamide (which is used for hematological and non-hematological malignancies) [4]. Ifosfamide-related Fanconi syndrome has been described in up to 5$7 \%$ of patients treated with this drug [5]. It may also cause nephrotoxicity, proximal tubulopathy, and glomerulopathy [6].

We outline two case reports of patients who received ifosfamide as chemotherapy, who presented with metabolic abnormalities compatible with Fanconi syndrome.

\section{Case Presentation}

\section{Case \#1}

A 23-year-old male patient, residing in an urban area, was diagnosed with Ewing's sarcoma in 2018 with staging T2N1Mx. The patient underwent chemotherapy with vincristine, doxorubicin, cyclophosphamide intercalated with ifosfamide and etoposide every 2-3 weeks (Table 1); after nine cycles doxorubicin was exchanged for actinomycin, and the patient received three more cycles of chemotherapy.

\section{TABLE 1: Chemotherapy cycle}

He showed tumor progression on the upper right limb which required disarticulation surgery and the restart of chemotherapy for six additional cycles. The last cycle was performed a week after an outpatient follow-up at Hospital San Vicente Fundación, in Medellín. Follow-up echocardiography showed two moving, hypoechogenic masses attached to the postero-medial papillary muscle, of sizes $8.6 \times 4.5 \mathrm{~mm}$ and $7.2 \times 5.3 \mathrm{~mm}$. Therefore, the patient was admitted to rule out endocarditis. Chest and abdomen computed tomography 
(CT) and bone scintigraphy were performed, with no metastatic involvement; aerobic and anaerobic blood cultures were negative. Further workup showed creatinine levels to be at $1.14 \mathrm{mg} / \mathrm{dL}$. The glomerular filtration rate (eGFR) was estimated through the CKD-EPI equation (Chronic Kidney Disease Epidemiology Collaboration) to be $90.14 \mathrm{ml} / \mathrm{min} / 1,73 \mathrm{~m}^{2}$ ); his urinalysis showed $1000 \mathrm{mg} / \mathrm{dL}$ glucosuria and $75 \mathrm{mg} / \mathrm{dL}$ proteinuria, with blood glucose less than $180 \mathrm{mg} / \mathrm{dl}$ (Figure 1) and glycated hemoglobin A1c of 5.9\%, which is in the pre-diabetes range. A tubulopathy was suspected, hence, arterial blood gas analysis was performed, which showed the $\mathrm{pH}$ to be $7.3, \mathrm{HCO} 3$ to be $23.1 \mathrm{mmol} / \mathrm{L}, \mathrm{PCO} 2$ to be $47.7 \mathrm{mmHg}$, and anion gap to be 12 (respiratory acidosis + metabolic acidosis with normal anion gap). Serum uric acid was found to be low at 2.1 $\mathrm{mg} / \mathrm{dL}$; the 24-hour urine protein was found to be at $1126 \mathrm{mg}$, with fractional excretion of phosphate to be at $30.7 \%$ and fractional excretion of potassium to be at $11.1 \%$. Tubulopathy was ruled out and Fanconi syndrome diagnosis was inferred due to Ifosfamide use. The oncology department withdrew the offending drug and nephrology prescribed oral bicarbonate therapy for two months. Later the arterial blood gases were found to be normal, showing a pH 7.43, PCO2 of $30 \mathrm{mmHg}, \mathrm{HCO} 3 \mathrm{of} 22.3 \mathrm{mmol} / \mathrm{L}$, and normal levels of potassium. Months later, cardiac masses were surgically resected, with the pathology department discovering metastatic involvement; new imaging studies demonstrated liver, pancreatic, left lung, gallbladder wall, bilateral paravertebral, and gluteus muscle involvement. Consequently, the patient underwent palliative care. The initial respiratory acidosis was not investigated but it could have been secondary to consumption of opioid analgesics or decreased muscle mass.

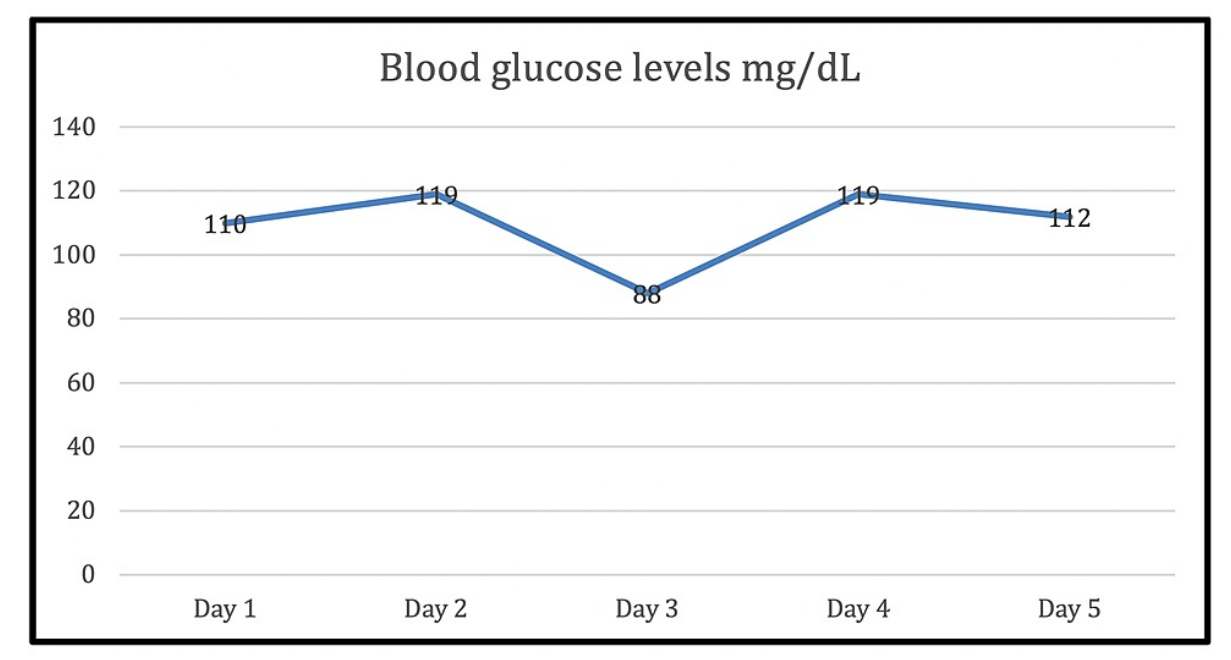

FIGURE 1: Blood glucose levels

\section{Case \#2}

A 44-year-old female patient, residing in an urban area, was diagnosed with aggressive extranodal B-cell lymphoma, with metastasis to the spine, pelvic ring, right femur, and pathologic L4 fracture and secondary nerve compression, in January 2019. She initially received six R-CHOP cycles (Rituximab, cyclophosphamide, doxorubicin, vincristine, and prednisone), 10 lumbar and three cervical radiotherapy sessions, which were discontinued due to a right hip fracture in December 2019, which required a total prosthetic replacement. Later, a pathology report showed relapse (germinal center diffuse large cell lymphoma).

A positron emission tomography (PET) performed in January 2020 showed countless lytic lesions on axial and appendicular bones. Hence, second-line therapy was started (rituximab, ifosfamide, carboplatin, and etoposide). Three days after second-line therapy was started, the patient presented with a febrile syndrome with no focus, therefore cefepime and vancomycin were started. However, no microbiological isolation was made and laboratory results showed low serum uric acid at $1.4 \mathrm{mg} / \mathrm{dL}$, low serum phosphate at $1.8 \mathrm{mg} / \mathrm{dL}$, normal lactic acid at $3.3 \mathrm{mg} / \mathrm{dL}$, low magnesium at $1.3 \mathrm{mg} / \mathrm{dL}$. Arterial blood gas analysis showed pH 7.28, HCO3 $12.1 \mathrm{mmol} / \mathrm{L}$, PCO2 $18 \mathrm{mmHg}$, sodium $142 \mathrm{mmol} / \mathrm{L}$, chloride $119 \mathrm{mmol} / \mathrm{L}$, and potassium at 3.1 $\mathrm{mmol} / \mathrm{L}$. Metabolic acidosis with normal anion gap was diagnosed, the renal function was preserved (creatinine $0.64 \mathrm{mg} / \mathrm{dL}$, with GFR through $2021 \mathrm{CKD}$-EPI of $108 \mathrm{~mL} / \mathrm{min} / 1,73 \mathrm{~m} 2$ ); urinalysis showed proteinuria (Table 2). Urinary electrolytes revealed urinary anion gap: sodium $128 \mathrm{mmol} / \mathrm{L}$, potassium 11.2 $\mathrm{mmol} / \mathrm{L}$, chloride $111 \mathrm{mmol} / \mathrm{L}$. Urinary anion gap was positive at 28 , however, urinary $\mathrm{pH}$ was $>6.5$, which could have altered urinary anion gap results. 


\section{Cureus}

\begin{tabular}{|c|c|c|}
\hline Characteristic & Value & Reference range \\
\hline Aspect & Clear & Clear/normal \\
\hline Color & Yellow & \\
\hline Glucose & Normal & \\
\hline Proteins (mg/dL) & 25 & Negative \\
\hline Bilirrubin (mg/dL) & Normal & Normal \\
\hline Urobilinogen (mg/dL) & Normal & Normal \\
\hline $\mathrm{pH}$ & 7 & $5-6$ \\
\hline Density & 1010 & $1010-1020$ \\
\hline Blood (RBC/uL) & 10 & Negative \\
\hline Ketonic bodies (mg/dL) & 5 & Negative \\
\hline Nitrites & Negative & Negative \\
\hline Leukocyte esterase & Negative & Negatve \\
\hline \multicolumn{3}{|l|}{ Urinary Sediment } \\
\hline Red blood cells & None observed & \\
\hline Leukocytes & 2/HPF & \\
\hline Bacteria & None observed & \\
\hline Epithelial cells & 1/HPF & \\
\hline Mucus & Scarce amount & \\
\hline
\end{tabular}

\section{TABLE 2: Urinalysis and urinary sediment}

Nephrology concluded that the metabolic acidosis with a normal anion gap, hypokalemia, low uric acid, hypophosphatemia, hypomagnesemia, and proteinuria with no GFR disturbance was compatible with Fanconi syndrome, probably related to Ifosfamide use as previous laboratory values were normal.

Intravenous bicarbonate therapy was started for one week, with acid-base and electrolyte normalization. And the Fanconi syndrome was found to be reversible. Oncology withdrew chemotherapy and third-line therapy was started with R-DHAOx (Rituximab, dexamethasone, cytarabine, oxaliplatin) for outpatient management.

\section{Discussion}

Fanconi syndrome is a disorder of the proximal tubule, which leads to malabsorption of electrolytes and other substances [1]. It may be acquired or inherited. It's usually acquired in adults. Its hereditary causes are cystinosis, galactosemia, mitochondrial diseases, fructose intolerance, tyrosinemia, Wilson's disease, and idiopathic ones. Among purchased drugs (Table 3), monoclonal gammopathies or toxic induced ones [7]. 


\section{Cureus}

Drugs associated with Fanconi syndrome

Nucleoside reverse transcriptase inhibitors

Acyclic nucleoside phosphonates

Aminoglycosides

Alkylating agents and platinum agents

Anticonvulsants

Antiparasitics

Histamine 2 blockers

Carbonic anhydrase inhibitors

Salicylate intoxication

Iron chelators
Lamivudine, stavudine

Cidofovir, adefovir, tenofovir

Gentamicin, tobramycin, amikacin

Ifosfamide, cisplatin, carboplatin

Valproic acid

Suramin

Ranitidine, cimetidine

Acetazolamide

Acetylsalicylic acid

Deferasirox

TABLE 3: Drugs

Adapted from [8]

Herein, we described two cases of ifosfamide-associated Fanconi syndrome. Among chemotherapy agents, ifosfamide is classified as an alkylating agent. Its active metabolites alkylate or bind with intracellular structures, including nucleic acids. Its cytotoxic action is mainly due to its binding to DNA and RNA, with protein synthesis inhibition. Ifosfamide is used as a chemotherapy agent for the treatment of sarcomas, lymphomas, breast cancer, testicular or pulmonary cancer. However, its use may have certain complications such as proximal tubulopathy, and Fanconi syndrome (whether it is associated with diabetes insipidus or not). The first case had glucosuria with normal serum glucose, metabolic acidosis with a normal anion gap, low serum uric acid, proteinuria, and increased phosphate and potassium excretion (Table 4). Hence, Fanconi syndrome was diagnosed. Even though it was an unlikely cause due to the age and lack of personal history of heavy metal intoxication; nor were tetracycline, antiviral, or azathioprine use was recorded; no monoclonal gammopathy findings were observed. The second patient presented with metabolic acidosis with a normal anion gap, hypokalemia, low uric acid, hypophosphatemia, hypomagnesemia, and proteinuria, with no renal function impairment (Table 4). Remarkably, a urinary anion gap was positive, although urinary $\mathrm{pH}$ was $>6.5$, which could lead to an unreliable urinary anion gap; however, it may also be associated with a concomitant type 1 tubular acidosis. Hereditary causes were unlikely, as admission laboratory workup was normal, no evidence of monoclonal gammopathy was observed, and the whole clinical picture started after chemotherapy and two antibiotic exposures (cefepime and vancomycin); the last two agents have not been associated with Fanconi syndrome or type 1 tubular acidosis. Among chemotherapy agents, first-line drugs were unlikely to be the cause as no laboratory abnormalities were observed. The second-line drugs were likely to be associated they were administered before the clinical presentation. Among second-line agents, Ifosfamide is strongly associated with both Fanconi syndrome and type 1 tubular acidosis. Therefore, it was considered as the most likely cause. The drug was withdrawn, electrolytes were replenished, and intravenous bicarbonate therapy was started, with normalization of laboratory values. 


\section{Cureus}

\begin{tabular}{|lll|}
\hline Laboratory values for both patients & & \\
Test & Case \#1 & 0.64 \\
Creatinine $\mathrm{mg} / \mathrm{dL}$ & 1.14 & Negative \\
Glucosuria $\mathrm{mg} / \mathrm{dL}$ & 1000 & 25 \\
Proteinuria orina ocasional $\mathrm{mg} / \mathrm{dL}$ & 75 & 7.28 \\
$\mathrm{pH}$ & 7.3 & 12.1 \\
$\mathrm{HCO} 3 \mathrm{mmol} / \mathrm{L}$ & 23.1 & 18 \\
PCO2 $\mathrm{mmHg}$ & 47.7 & 11 \\
Anion gap & 12 & 1.4 \\
Serum uric acid $\mathrm{mg} / \mathrm{dL}$ & 2.1 & 1.8 \\
Phosphate $\mathrm{mg} / \mathrm{dL}$ & & \\
\hline
\end{tabular}

TABLE 4: Laboratory values.

The mechanism underlying ifosfamide-induced Fanconi syndrome isn't well established. As it is a pro-drug and it needs to be activated by the hepatic cytochrome oxidase. A theory related to ifosfamide metabolismrelated products has been proposed [9]. These products are selectively taken by the organic cation transporter 2 (OCT2), which is found on the basal-lateral aspect of the proximal tubule cells; a reduction of dehydrogenase has also been observed [10]. Additionally, chloroacetaldehyde metabolite accumulates on the proximal tubule cells and reduces antioxidant glutathione and adenosine triphosphate levels are involved. This process is related to endocytosis and intracellular protein processing reduction [11].

In conclusion, ifosfamide, just as cyclophosphamide, is an effective drug against malignant neoplasms; however, nephrotoxic effects are common, and these may be permanent and irreversible. Strict follow-up of renal and tubular function is mandatory (urinalysis, serum, and urine electrolyte measurement, arterial blood gas analysis).

\section{Conclusions}

The most common causes of Fanconi syndrome in adults are: endogenous or exogenous toxins such as heavy metals, drugs, or dysproteinemias. Among drugs, plenty have been associated with Fanconi syndrome, such as: antibiotics, antiviral therapy, anticonvulsants, and chemotherapy such as ifosfamide. It may also cause nephrotoxicity, proximal tubulopathy and glomerulopathy. Patients who receive ifosfamide must be closely monitored for renal impairment to avoid this rare but fatal complication.

\section{Additional Information \\ Disclosures}

Human subjects: Consent was obtained or waived by all participants in this study. Conflicts of interest: In compliance with the ICMJE uniform disclosure form, all authors declare the following: Payment/services info: All authors have declared that no financial support was received from any organization for the submitted work. Financial relationships: All authors have declared that they have no financial relationships at present or within the previous three years with any organizations that might have an interest in the submitted work. Other relationships: All authors have declared that there are no other relationships or activities that could appear to have influenced the submitted work.

\section{References}

1. John W. Foreman: Fanconi syndrome in adulthood. The role of early diagnosis and treatment Comprehensive Clinical Nephrology. ELSEVIER, 303-306; 2019. 6:586-594.

2. Karatzas A, Paridis D, Kozyrakis D, Tzortzis V, Samarinas M, Dailiana Z, Karachalios T: Fanconi syndrome in the adulthood. The role of early diagnosis and treatment. J Musculoskelet Neuronal Interact. 2017, 17:303-6.

3. Hall AM, Bass P, Unwin RJ: Drug-induced renal Fanconi syndrome. QJM. 2014, 107:261-9. 10.1093/qjmed/hct258

4. O'Sullivan D: Late effects of chemotherapeutic agents on renal function in childhood cancer survivors: a review of the literature. Ir J Med Sci. 2017, 186:49-55. 10.1007/s11845-016-1473-Z

5. Ho PT, Zimmerman K, Wexler LH, et al.: A prospective evaluation of ifosfamide-related nephrotoxicity in children and young adults. Cancer. 1995, 76:2557-64. 10.1002/1097-0142(19951215)76:12<2557::aid- 


\section{Cureus}

cncr2820761223>3.0.co;2-9

6. Van Dyk JJ, Falkson HC, Van der Merwe AM, Falkson G: Unexpected toxicity in patients treated with iphosphamide. Cancer Res. 1972, 32:921-4.

7. Tu H, Mou L, Zhu L, Jiang Q, Gao DS, Hu Y: Acquired Fanconi syndrome secondary to light chain deposition disease associated with monoclonal gammopathy of renal significance: A case report. Medicine (Baltimore). 2018, 97:e12027. 10.1097/MD.0000000000012027

8. Izzedine H, Launay-Vacher V, Isnard-Bagnis C, Deray G: Drug-induced Fanconi's syndrome. Am J Kidney Dis. 2003, 41:292-309. 10.1053/ajkd.2003.50037

9. Furlanut M, Franceschi L: Pharmacology of ifosfamide. Oncology. 2003, 65 Suppl 2:2-6. 10.1159/000073350

10. Ciarimboli G, Holle SK, Vollenbröcker B, et al.: New clues for nephrotoxicity induced by ifosfamide: preferential renal uptake via the human organic cation transporter 2. Mol Pharm. 2011, 8:270-9. 10.1021/mp100329u

11. Yaseen Z, Michoudet C, Baverel G, Dubourg L: Mechanisms of the ifosfamide-induced inhibition of endocytosis in the rat proximal kidney tubule. Arch Toxicol. 2008, 82:607-14. 10.1007/s00204-007-0275-5 